\title{
Physical activity levels in 10- to 11 -year-olds: clustering of psychosocial correlates
}

\author{
Greet Cardon $^{1, *}$, Renaat Philippaerts ${ }^{1}$, Johan Lefevre ${ }^{2}$, Lynn Matton² ${ }^{2}$ Katrien Wijndaele ${ }^{1}$, \\ Anne-Line Balduck ${ }^{1}$ and Ilse De Bourdeaudhuij ${ }^{1}$ \\ 'Department of Movement and Sports Sciences, Ghent University, Watersportlaan 2, B-9000 Gent, Belgium: \\ ${ }^{2}$ Department of Sports and Movement Sciences, KU Leuven, Leuven, Belgium
}

Submitted 7 December 2004: Accepted 21 March 2005

\begin{abstract}
Objectives: To evaluate gender differences for levels of physical activity, for sedentary behaviour and for psychosocial correlates in children, to evaluate whether psychosocial correlates cluster in meaningful ways and to examine whether physical activity and sedentary behaviour differ between children of clusters, differentiated by the level of perceived barriers and benefits, attitudes, social support and self-efficacy. Design: Cross-sectional study using the Flemish Physical Activity Questionnaire.

Setting: Questionnaires to be filled out by the children and one of their parents, contacted through the school system.

Subjects: A sample of 1124 10- to 11 -year-olds ( 579 boys and 545 girls).

Results: Girls were found to be less active than boys, with boys scoring better for social support, perceived benefits and self-efficacy compared with girls. The way of clustering differed between boys and girls. Boys were allocated to three clusters: one cluster with positive correlates towards physical activity, labelled 'positives'; one with negative correlates, labelled 'negatives'; and one characterised mainly by high perceived barriers, labelled 'hindered'. In both genders the highest levels of physical activity were found in the 'positives', the lowest in the 'negatives'. In girls a fourth cluster was identified, characterised mainly by low perceived barriers and low social support. Physical activity levels in the girls of this cluster, labelled 'indifferents', were the second highest.

Conclusions: More research is needed to further characterise these clusters. To prevent the physical activity decline during the transition from childhood to adulthood, novel interventions need to be explored that focus on children of the clusters with the most negative correlates.
\end{abstract}

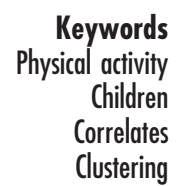

In all age groups the health benefits of regular physical activity are well documented ${ }^{1,2}$. Nevertheless, a sedentary lifestyle is prevalent in most industrialised countries ${ }^{3,4}$. While children are more active than adults, evidence suggests that there is a sizeable proportion of young people who have activity levels lower than those desirable for good health and that physical activity declines from 8 to 18 years of age $e^{2,5-7}$. Furthermore, tracking studies have revealed that low levels of physical activity remain stable from adolescence into adulthood ${ }^{8,9}$. Therefore all young people should be encouraged and given opportunities to accumulate moderate to vigorous physical activity, including sports activities, for at least $60 \mathrm{~min}$ and up to several hours daily, and the importance of lifelong physical activity should be emphasised at a young age $^{2,10}$. Moreover, the epidemic of childhood obesity that swept through the industrialised countries in the last decade $^{11,12}$ has made the advocacy of physical activity popular in children.
It is obvious that physical activity intervention approaches have to be matched to the developmental level of the target group and that the promotion of physical activity has to be based upon its most important determinants in that population ${ }^{13}$. In the literature psychological correlates of physical activity in adolescents have been studied extensively. However, Sallis et al. ${ }^{14}$ reported that correlates of physical activity may differ between children and adolescents. Mainly due to measurement limitations ${ }^{15}$, less is known about correlates of physical activity in children than in adolescents. In the same vein, little is known about correlates of sedentary behaviours in children ${ }^{2}$. Moreover, physical activity levels and single markers of sedentary behaviour are not strongly correlated $^{2}$ and correlates of physical activity are likely to differ from correlates of sedentary behaviours ${ }^{16}$. It can be concluded that there is a need to evaluate the correlates of physical activity and sedentary behaviours in children in order to understand the appeal of activity and the appeal 
of inactivity in this age group, and thus to intervene more efficaciously.

The transition from childhood to puberty with its biological and social implications is an important intervening step for physical activity transition from childhood to adulthood $^{17}$. Since correlates of physical activity and sedentary behaviour may differ between preadolescents and adolescents ${ }^{14}$ and since studies on psychosocial correlates are still sparse in preadolescents, they are worth studying to intervene more effectively in this age group. Furthermore, psychosocial determinants are often related to each other ${ }^{18}$ and no study could be located evaluating clusters of correlates in children. Evaluating clusters of correlates versus separate determinants has the advantage that the most discriminating correlates within clusters can be identified, which gives the opportunity to develop intervention strategies more focused on specific correlates.

The present study aimed to evaluate gender differences for levels of physical activity, levels of sedentary behaviour and psychosocial correlates in a sample of 10- to 11-yearold boys and girls, to evaluate whether psychosocial correlates cluster in meaningful ways and to examine whether levels of physical activity and sedentary behaviour differ between children of clusters, differentiated by the level of perceived barriers and benefits, attitudes, social support and self-efficacy.

\section{Material and methods}

\section{Participants and procedure}

The present study population consisted of a sample of 112410 - to 11-year-old children ( 579 boys and 545 girls), from 27 randomly selected elementary schools in Flanders, Belgium. Schools were representative with respect to school system (catholic and governmental). Thirty per cent of the children lived in a village with less than 20000 inhabitants, 40\% in a small city (between 20000 and 100000 inhabitants) and 20\% in a large city (more than 100000 inhabitants). Seventy per cent of the fathers and $60 \%$ of the mothers were white-collar workers. Children were asked at school to complete a questionnaire at home together with one of their parents. A letter for the parents was added to the questionnaire, clearly instructing that one of the parents had to assist the child in completing the entire physical activity questionnaire and that the parent had to explain the questions if necessary. Questionnaires were collected at school. The study was approved by the different educational authorities and by the ethical committee of the University Hospital of Ghent University.

\section{Instruments}

Personal characteristics (age, gender, weight and height), socio-economic status (occupation of both parents), residential density (less than 2000 inhabitants, between 2000 and 20000 inhabitants, between 20000 and 100000 inhabitants and more than 100000 inhabitants), physical activity levels and psychosocial determinants of physical activity were assessed making use of the Flemish Physical Activity Questionnaire (FPAQ), to be filled out with parental assistance.

Reliability of the FPAQ was evaluated in a preliminary sample of 519 - to 11-year-olds ${ }^{19}$. The intraclass correlation coefficients (ICCs) were found to be relatively high for the physical activity (PA) indices (total PA index, active transportation included: ICC $=0.82$; total PA index without active transportation: ICC $=0.86$ ), for the sedentary index ( ICC $=0.78)$ and for the psychosocial correlates (attitude index: ICC $=0.83$; social support index: ICC $=0.70 ; \quad$ self-efficacy: $\quad$ ICC $=0.68 ; \quad$ barriers: ICC $=0.76$; benefits: $\quad$ ICC $=0.78$ ). Only the questions regarding transportation to and from school and during leisure time were found to be unreliable (ICC $=0.26)$ and were therefore excluded from further analyses. For validation of the physical activity part of the questionnaire, accelerometer counts were compared with physical activity reports in the same sample of 51 children. The correlations between the questionnaire and the accelerometer counts (ranging from $r=0.27, \quad P<0.05$ to $r=0.50, P<0.01)$ were slightly higher than correlations in other studies in this age group. From the preliminary study it could be concluded that the FPAQ had good reliability and acceptable validity to evaluate physical activity in 9- to 11-year-olds. The measures for sedentary behaviour and psychosocial correlates were found to be reliable; however, the validity of these measures could not be evaluated.

\section{Physical activity levels}

The FPAQ was developed to assess levels of physical activity in diverse domains, such as school activity, leisuretime activity and sedentary activities, in a usual week.

Sports participation was assessed by asking the children and one of their parents to select their three most important sports out of a list of 178 sports. Both organised and nonorganised sports were included. For each of these sports, frequency (from once a year to more than once a day) and duration (from number of hours per year to number of hours per week) were reported. Sport at school except PE (Physical Education) was assessed by asking pupils the extent of sport or physical activity organised during lunch break, during and after study hours at school, on Wednesday afternoon, or at class or school tournaments. Children reported whether they participated and how much time they spent in these activities. A sport at school except PE index was calculated by summation of the time spent in these activities and was expressed in hours per week. Children were also asked what they usually did during breaks at school (sit, stand, walk or be active). Additionally two questions were included asking for the number of times per week that participants engaged in vigorous activity for at least $20 \mathrm{~min}$, and for the number of 
days per week that participants engaged in continuous moderate activity for at least $60 \mathrm{~min}$. Sedentary behaviour was assessed asking for how many hours per day participants watched television or video, played computer games or did other sedentary activities during an average weekday and during an average weekend day. A sedentary behaviour index was calculated by summation of the time spent on these behaviours, expressed in hours per day.

\section{Psychosocial correlates of physical activity}

General-affective attitude, social influences, self-efficacy and perceived benefits and barriers were assessed by 28 items with a 5-point Likert scale. Questions were selected and adopted from the study of Deforche et al. ${ }^{20}$ with children and adolescents. General-affective attitudes towards physical activity were assessed using bipolar adjectives. Participants were asked whether sports and physical activity are 'not pleasant/pleasant', 'dangerous/ safe', 'bad/good', 'healthy/unhealthy' and 'stupid/smart'. Social support was assessed by asking respondents how frequently their family, friends and PE teacher encouraged them to be physically active. A social support index was calculated by summation of the three social support scores (range 3-15). Self-efficacy was measured by asking how easy or difficult it was found to continue with sports or physical activity for $30 \mathrm{~min}$ to $1 \mathrm{~h}$ per day. Perceived benefits and barriers with regard to physical activity were investigated by asking respondents to rate their agreement with possible effects of sports and physical activity (nine items: weight and physical appearance, health and fitness, social interaction, pleasure, competition, stress and depression, earn money, admiration from others, relaxation from school work) and the frequency with which barriers prevented them from exercising (10 items: lack of time, lack of discipline, lack of interest, health problems, personal problems, too expensive, lack of facilities, not the sporty type, facilities too far, lack of transportation). Cronbach's $\alpha$ reliability coefficients were computed for the different indices (general-affective attitudes: $\alpha=0.77$; social support: $\alpha=0.56$; benefits: $\alpha=0.72$; barriers: $\alpha=0.80$ ).

\section{Data analysis}

Data were analysed using SPSS for Windows, version 11.0 (SPSS Inc., Chicago, IL, USA). To evaluate gender differences for personal characteristics, for psychosocial correlates and for levels of physical activity and sedentary behaviour, independent samples $t$-testing was used. To identify groups of children who share similar patterns of correlates, hierarchical ( $K$-means) cluster analyses were performed on standardised scores ( $Z$-scores) for both genders separately. Cluster analysis is an exploratory statistical technique which allocates individuals to groups based on characteristics they have in common. A $Z$-score of \pm 0.5 was used as a criterion for identifying distinguishing characteristics within each cluster. Differences in levels of physical activity and sedentary behaviour between the clusters were tested using analysis of variance with least significant difference post hoc testing. The level of significance was set at 0.05 for all analyses.

\section{Results}

\section{Gender differences}

In the total sample significantly higher levels of physical activity and significantly more sedentary behaviour were reported in boys than in girls (see Table 1). Gender differences for the correlates are presented in Table 2. Attitudes for physical activity did not differ significantly between genders, except for 'doing sports and PA is fun', which scored higher in boys compared with girls. Boys reported more social support from their family members and friends than girls, while social support from the PE teacher did not differ significantly between genders.

Self-efficacy scores were significantly higher in boys than girls. Also, scores for perceived benefits were higher in boys, except for 'lose weight and look good', which did not differ significantly between genders. Barriers for physical activity were not perceived differently by the genders.

\section{Cluster analyses}

Among boys

In boys three clusters of correlates were identified. Figure 1 shows the cluster profiles expressed in standardised scores among boys. In cluster 1 (41\% of

Table 1 Characteristics and levels of physical activity (PA) and sedentary behaviour (mean \pm standard deviation) in the total group and in boys and girls separately

\begin{tabular}{|c|c|c|c|c|}
\hline & Total group $(n=1124)$ & Boys $(n=579)$ & Girls $(n=545)$ & $t$-value and significance \\
\hline Age (years) & $10.6 \pm 0.5$ & $10.6 \pm 0.5$ & $10.6 \pm 0.5$ & 1.1 \\
\hline Weight (kg) & $38.3 \pm 8.2$ & $37.9 \pm 8.0$ & $38.7 \pm 8.3$ & 1.6 \\
\hline Height $(\mathrm{cm})$ & $148.1 \pm 8.4$ & $147.8 \pm 8.3$ & $148.4 \pm 8.5$ & 1.3 \\
\hline Sports outside school $\left(\right.$ h week $\left.^{-1}\right)$ & $2.9 \pm 2.9$ & $3.4 \pm 3.1$ & $2.3 \pm 2.5$ & $6.2^{\star \star}$ \\
\hline Sports at school (h week $\left.{ }^{-1}\right)$ & $2.6 \pm 1.8$ & $3.0 \pm 1.8$ & $2.2 \pm 1.8$ & $7.1^{\star *}$ \\
\hline Frequency of 20 min vigorous PA (times week ${ }^{-1}$ ) & $2.47 \pm 1.92$ & $2.9 \pm 2.1$ & $2.1 \pm 1.7$ & $6.4^{\star \star}$ \\
\hline Frequency of 60 min moderate PA (times week ${ }^{-1}$ ) & $1.92 \pm 1.65$ & $2.2 \pm 1.8$ & $1.6 \pm 1.5$ & $5.7^{\star \star}$ \\
\hline Activity level during breaks at school $(1-4)$ & $3.6 \pm 0.7$ & $3.8 \pm 0.5$ & $3.3 \pm 0.7$ & $10.6^{\star *}$ \\
\hline Sedentary behaviour during week (h day ${ }^{-1}$ ) & $3.2 \pm 1.8$ & $3.4 \pm 1.9$ & $3.1 \pm 1.8$ & $3.2^{\star *}$ \\
\hline
\end{tabular}

${ }^{\star}, P<0.01 ;{ }^{* *}, P<0.001$. 
Table 2 Correlates (mean score \pm standard deviation) in the total group and in boys and girls separately

\begin{tabular}{|c|c|c|c|c|}
\hline & $\begin{array}{l}\text { Total group } \\
(n=1124)\end{array}$ & $\begin{array}{c}\text { Boys } \\
(n=579)\end{array}$ & $\begin{array}{c}\text { Girls } \\
(n=545)\end{array}$ & $\begin{array}{l}t \text {-value and } \\
\text { significance }\end{array}$ \\
\hline \multicolumn{5}{|l|}{ Attitudes (5-point scale) } \\
\hline \multicolumn{5}{|l|}{ Doing sports and physical activity is } \\
\hline Fun & $4.31 \pm 0.94$ & $4.37 \pm 0.82$ & $4.23 \pm 0.85$ & $2.8^{\star}$ \\
\hline Safe & $3.49 \pm 0.69$ & $3.50 \pm 0.71$ & $3.49 \pm 0.66$ & 0.4 \\
\hline Good & $4.42 \pm 0.67$ & $4.43 \pm 0.70$ & $4.41 \pm 0.68$ & 0.5 \\
\hline Healthy & $4.52 \pm 0.59$ & $4.54 \pm 0.59$ & $4.49 \pm 0.59$ & 1.5 \\
\hline Smart & $4.18 \pm 0.71$ & $4.16 \pm 0.74$ & $4.19 \pm 0.72$ & 0.7 \\
\hline Mean & $4.17 \pm 0.72$ & $4.20 \pm 0.71$ & $4.15 \pm 0.72$ & 1.5 \\
\hline \multicolumn{5}{|l|}{ Social support (5-point scale) } \\
\hline \multicolumn{5}{|l|}{ Encouragement to be active by } \\
\hline Family members & $4.16 \pm 0.98$ & $4.24 \pm 0.94$ & $4.06 \pm 1.02$ & $3.1^{*}$ \\
\hline Friends & $3.45 \pm 1.17$ & $3.59 \pm 1.19$ & $3.29 \pm 1.13$ & $4.1^{* *}$ \\
\hline PE teacher & $3.44 \pm 1.41$ & $3.43 \pm 1.42$ & $3.45 \pm 1.41$ & 0.2 \\
\hline Mean & $3.70 \pm 1.19$ & $3.76 \pm 1.18$ & $3.63 \pm 1.19$ & $2.6^{*}$ \\
\hline Self-efficacy for physical activity and sports (5-point scale) & $3.69 \pm 0.97$ & $3.85 \pm 0.97$ & $3.53 \pm 0.97$ & $5.4^{\star \star}$ \\
\hline \multicolumn{5}{|l|}{ Perceived benefits (5-point scale) } \\
\hline Lose weight and look good & $2.68 \pm 1.31$ & $2.61 \pm 1.34$ & $2.76 \pm 1.27$ & 1.9 \\
\hline Improve my health and condition & $4.21 \pm 0.86$ & $4.31 \pm 0.80$ & $4.09 \pm 0.90$ & $4.4^{\star *}$ \\
\hline Being together with friends/meet new people & $3.96 \pm 0.99$ & $4.05 \pm 0.95$ & $3.85 \pm 1.01$ & $3.3^{\star \star}$ \\
\hline Have fun & $4.53 \pm 0.73$ & $4.59 \pm 0.69$ & $4.46 \pm 0.77$ & $2.9^{\star}$ \\
\hline Play competition and feel the kick of winning & $3.01 \pm 1.40$ & $3.42 \pm 1.38$ & $2.57 \pm 1.28$ & $10.5^{\star *}$ \\
\hline Feel less stress and unhappiness & $3.08 \pm 1.32$ & $3.19 \pm 1.35$ & $2.95 \pm 1.27$ & $3.0^{*}$ \\
\hline Earn money & $1.47 \pm 0.89$ & $1.63 \pm 1.06$ & $1.30 \pm 0.62$ & $6.4^{\star \star}$ \\
\hline Other people admire me & $2.57 \pm 1.29$ & $2.79 \pm 1.32$ & $2.34 \pm 1.23$ & $5.7^{\star \star}$ \\
\hline Counterbalance for my homework & $3.05 \pm 1.32$ & $3.24 \pm 1.35$ & $2.84 \pm 1.26$ & $5.0^{* *}$ \\
\hline Mean & $3.18 \pm 1.12$ & $3.33 \pm 1.14$ & $3.03 \pm 1.07$ & $7.8^{\star \star}$ \\
\hline \multicolumn{5}{|l|}{ Perceived barriers (5-point scale) } \\
\hline Lack of time & $2.57 \pm 1.26$ & $2.55 \pm 1.28$ & $2.59 \pm 1.23$ & 0.5 \\
\hline Lack of discipline & $2.06 \pm 1.10$ & $2.01 \pm 1.10$ & $2.11 \pm 1.09$ & 1.4 \\
\hline Lack of interest & $1.99 \pm 1.18$ & $1.95 \pm 1.19$ & $2.04 \pm 1.15$ & 1.4 \\
\hline Health (sickness, injury, etc.) & $1.72 \pm 1.00$ & $1.78 \pm 1.05$ & $1.67 \pm 0.93$ & 1.8 \\
\hline Personal problems & $1.58 \pm 0.89$ & $1.62 \pm 0.91$ & $1.55 \pm 0.87$ & 1.3 \\
\hline Not the sporty type & $1.84 \pm 1.13$ & $1.79 \pm 1.14$ & $1.89 \pm 1.12$ & 1.5 \\
\hline Too expensive & $1.75 \pm 0.95$ & $1.70 \pm 0.91$ & $1.80 \pm 0.99$ & 1.7 \\
\hline Lack of infrastructure & $1.92 \pm 1.08$ & $1.91 \pm 1.09$ & $1.92 \pm 1.07$ & 0.1 \\
\hline Infrastructure too far & $2.03 \pm 1.15$ & $2.02 \pm 1.18$ & $2.05 \pm 1.12$ & 0.5 \\
\hline Lack of transportation & $1.92 \pm 1.09$ & $1.89 \pm 1.09$ & $1.95 \pm 1.09$ & 1.0 \\
\hline Mean & $1.97 \pm 1.08$ & $1.95 \pm 1.10$ & $1.99 \pm 1.07$ & 0.9 \\
\hline
\end{tabular}

$\mathrm{PE}-$ Physical Education.

${ }^{\star}, P<0.01 ;{ }^{*}, P<0.001$.

the sample, $n=223)$ high scores for attitudes $(Z=0.66)$, benefits $(Z=0.50)$, self-efficacy $(Z=0.60)$ and social support $(Z=0.56)$ clustered with low scores for perceived barriers $(Z=-0.73)$. Based on these

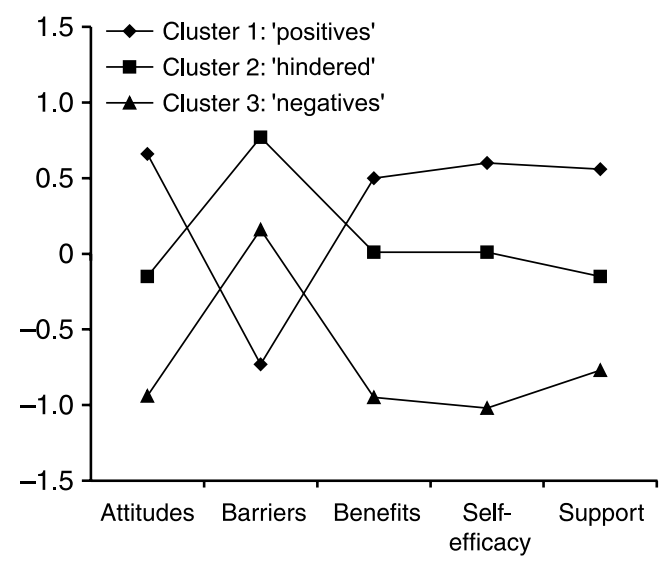

Fig. 1 Standard scores of cluster centres on correlates in boys characteristics, boys in cluster 1 were labelled 'positives'. Cluster 2 (35\% of the sample, $n=186)$ was characterised by boys with high scores for barriers $(Z=0.77)$ and low to average scores for attitude ( $Z=-0.15)$, benefits $(Z=0.01)$, self-efficacy $(Z=0.01)$ and social support $(Z=-0.15)$. Based on the characteristics from the profile, boys of cluster 2 were labelled 'hindered'. In cluster 3 (24\% of the sample, $n=127)$ low scores for attitude $(Z=-0.94)$, benefits $(Z=-0.95)$, self-efficacy $(Z=-1.02)$ and social support $(Z=-0.77)$ were reported (barriers, $Z=0.16)$. Boys in cluster 3 were labelled 'negatives'. All physical activity measures differed significantly between the clusters, while sedentary behaviour did not differ significantly (see Table 3). According to post boc analyses physical activity differences were significant between all clusters except for the difference in activity levels during breaks between clusters 2 and 3, which was not significant. The level of significance was $P<0.001$ for all significant cluster differences, except 
Table 3 Involvement in school sports and sports outside school, frequency of moderate and vigorous physical activity (PA), activity levels during breaks and sedentary behaviour (mean score \pm standard deviation) in the three clusters of boys

\begin{tabular}{|c|c|c|c|c|c|}
\hline & $\begin{array}{c}\text { Cluster 1: } \\
\text { 'positives' } \\
(n=223,41 \%)\end{array}$ & $\begin{array}{c}\text { Cluster 2: } \\
\text { 'hindered' } \\
(n=186,35 \%)\end{array}$ & $\begin{array}{c}\text { Cluster 3: } \\
\text { 'negatives' } \\
(n=127,24 \%)\end{array}$ & $F$ & $P$-value \\
\hline Sports outside school (h week ${ }^{-1}$ ) & $5.0 \pm 3.4^{\mathrm{a}}$ & $3.1 \pm 2.6^{b}$ & $2.0 \pm 2.7$ & 30.7 & $<0.001$ \\
\hline Sports at school $\left(\mathrm{h} \mathrm{week}^{-1}\right)$ & $3.5 \pm 1.6^{\mathrm{a}}$ & $3.0 \pm 1.8^{b}$ & $2.2 \pm 1.8$ & 15.0 & $<0.001$ \\
\hline Frequency of 20 min vigorous PA (times week ${ }^{-1}$ ) & $3.7 \pm 2.8^{\mathrm{a}}$ & $2.8 \pm 2.1^{b}$ & $1.9 \pm 1.9$ & 23.1 & $<0.001$ \\
\hline Frequency of $60 \mathrm{~min}$ moderate PA (times week ${ }^{-1}$ ) & $2.8 \pm 1.7^{\mathrm{a}}$ & $2.1 \pm 1.6^{b}$ & $1.6 \pm 1.5$ & 16.4 & $<0.001$ \\
\hline Activity level during breaks at school & $3.9 \pm 0.7^{\mathrm{a}}$ & $3.7 \pm 0.6$ & $3.7 \pm 0.6$ & 3.9 & $<0.05$ \\
\hline Sedentary behaviour $\left(\mathrm{h} \mathrm{day}^{-1}\right)$ & $3.5 \pm 1.9$ & $3.5 \pm 1.9$ & $3.5 \pm 2.0$ & 0.1 & NS \\
\hline
\end{tabular}

NS - not significant.

a Significantly higher than clusters 2 and 3 .

${ }^{\mathrm{b}}$ Significantly higher than cluster 3.

for the frequency of moderate physical activity between clusters 2 and $3(P=0.04)$.

\section{Among girls}

In girls clustering of correlates resulted in four clusters. Figure 2 shows the cluster profiles expressed in standardised scores among girls. In cluster 1 (33\% of the sample, $n=168)$ high scores for attitudes $(Z=0.62)$, benefits $(Z=0.53)$, self-efficacy $(Z=0.59)$ and social support $(Z=0.88)$ clustered with low barriers $(Z=-0.54)$. Girls in cluster 1 were labelled 'positives'. Cluster 2 (26\% of the sample, $n=129)$ comprised girls with low scores for barriers $(Z=-0.57)$ and social support $(Z=-0.76)$, but low to average scores for attitudes $(Z=0.19)$, benefits $(Z=-0.44)$ and self-efficacy $(Z=0.37)$. Girls in cluster 2 were labelled 'indifferents'. Cluster 3 (16\% of the sample, $n=80$ ) was characterised by high barriers $(Z=1.28)$ and high benefits $(Z=0.73)$ combined with low self-efficacy $(Z=-0.50)$ and low to average scores for attitudes $(Z=0.14)$ and social support $(Z=0.15)$. Based on these characteristics, girls of this

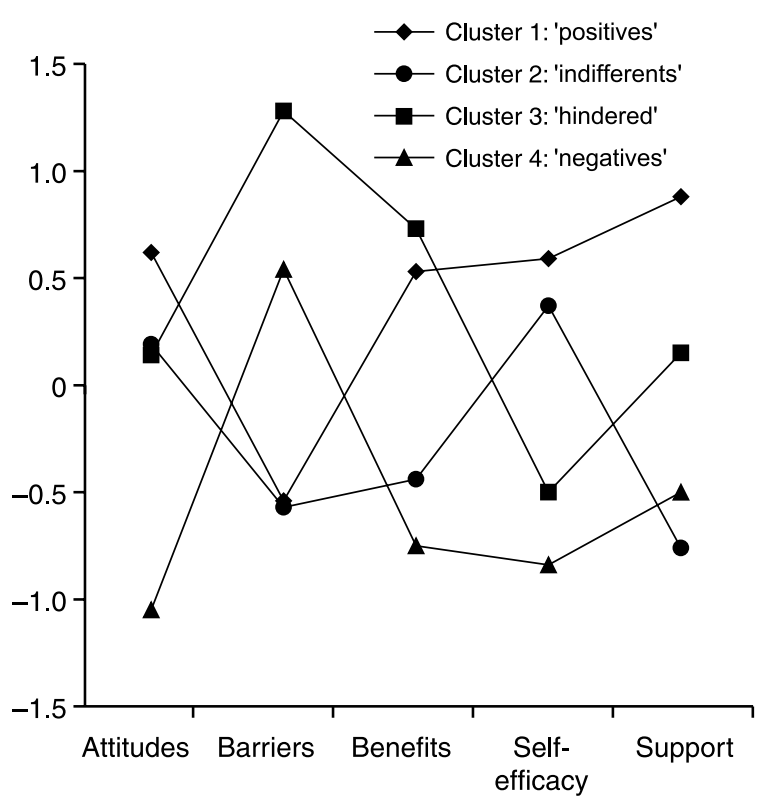

Fig. 2 Standard scores of cluster centres on correlates in girls cluster were labelled 'hindered'. In cluster 4 (25\% of the sample, $n=125)$ low scores for attitudes $(Z=-1.05)$, benefits $(Z=-0.75)$, self-efficacy $(Z=-0.84)$ and social support $(Z=-0.50)$ clustered with high scores for perceived barriers $(Z=0.54)$. Based on these characteristics, girls of cluster 4 were labelled 'negatives'. All measures of physical activity differed significantly between the four clusters, while measures of sedentary behaviour did not differ significantly (see Table 4).

Post hoc analyses revealed significantly higher scores for sports outside school $(P<0.001)$, sports at school $(P<0.001)$, frequency of moderate physical activity $(P<0.01)$, frequency of vigorous physical activity $(P<0.001)$ and activity level during breaks $(P<0.01)$ in the 'positives' (cluster 1) than in the 'hindered' (cluster 3) and the 'negatives' (cluster 4). The 'positives' (cluster 1) also scored significantly higher than the 'indifferents' (cluster 2) for sports outside school $(P<0.001)$ and sports at school $(P<0.01)$, while differences for frequency of moderate physical activity and frequency of vigorous physical activity were not significant between clusters 1 and 2 . The cluster 'indifferents' scored significantly higher for sports at school $(P<0.05)$ and for frequency of physical activity of moderate intensity $(P<0.01)$ than clusters 3 and 4 . Other cluster differences were not significant.

\section{Discussion}

The aims of the present study were to examine the clustering of correlates in 10- to 11-year-olds and to evaluate whether levels of physical activity and sedentary behaviour differ between clusters of common reports of attitudes, barriers, benefits, self-efficacy and social support in relation to physical activity. The present study findings empirically validate the social-cognitive constructs hypothesised to be associated with physical activity in youth. Identifying clusters of psychosocial correlates of physical activity in 10- to 11-year-olds could inform efforts that seek to prevent the decrease of physical activity levels during the transition from childhood to puberty. However, it needs to be taken into account that intervention guidelines, derived from the present study, need further 
Table 4 Involvement in school sports and sports outside school, frequency of moderate and vigorous physical activity (PA), activity levels during breaks and sedentary behaviour (mean score \pm standard deviation) in the four clusters of girls

\begin{tabular}{|c|c|c|c|c|c|c|}
\hline & $\begin{array}{c}\text { Cluster 1: } \\
\text { 'positives' } \\
(n=168,33 \%)\end{array}$ & $\begin{array}{c}\text { Cluster 2: } \\
\text { 'indifferents' } \\
(n=129,26 \%)\end{array}$ & $\begin{array}{c}\text { Cluster 3: } \\
\text { 'hindered' } \\
(n=80,16 \%)\end{array}$ & $\begin{array}{c}\text { Cluster 4: } \\
\text { 'negatives' } \\
(n=125,25 \%)\end{array}$ & $F$ & $P$-value \\
\hline Sports outside school (h week ${ }^{-1}$ ) & $3.2 \pm 2.4^{\mathrm{a}}$ & $2.1 \pm 2.0$ & $1.8 \pm 1.9$ & $1.6 \pm 2.6$ & 8.0 & $<0.001$ \\
\hline 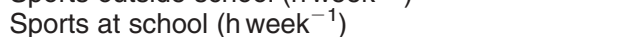 & $2.8 \pm 1.7^{\mathrm{a}}$ & $2.2 \pm 1.7^{\mathrm{b}}$ & $1.8 \pm 1.6$ & $1.5 \pm 1.6$ & 10.6 & $<0.001$ \\
\hline Frequency of 20 min vigorous PA (times week ${ }^{-1}$ ) & $2.6 \pm 1.8^{\mathrm{b}}$ & $2.2 \pm 1.6$ & $1.8 \pm 1.4$ & $1.8 \pm 1.7$ & 4.2 & $<0.01$ \\
\hline Frequency of 60 min moderate PA (times week ${ }^{-1}$ ) & $2.1 \pm 1.6^{\mathrm{b}}$ & $1.8 \pm 1.2^{\mathrm{b}}$ & $1.3 \pm 1.5$ & $1.3 \pm 1.5$ & 4.8 & $<0.01$ \\
\hline Activity level during breaks at school & $3.6 \pm 0.7^{b}$ & $3.4 \pm 0.6$ & $3.2 \pm 0.5$ & $3.2 \pm 0.6$ & 4.6 & $<0.01$ \\
\hline Sedentary behaviour $\left(\mathrm{h} \mathrm{day}^{-1}\right)$ & $3.1 \pm 1.9$ & $3.1 \pm 1.8$ & $2.9 \pm 1.8$ & $3.3 \pm 1.8$ & 0.7 & NS \\
\hline
\end{tabular}

NS - not significant.

a Significantly higher than clusters 2, 3 and 4

${ }^{\mathrm{b}}$ Significantly higher than clusters 3 and 4 .

evaluation and that, from a public health perspective, targeted and tailored interventions are not necessarily feasible, especially if an intervention is to be delivered in schools or other community settings.

Consistent with results in the literature ${ }^{2,14}$, girls were found to be less active than boys, advocating special efforts to increase physical activity in girls. The fact that boys scored better for social support, perceived benefits and self-efficacy may be responsible for the higher physical activity levels in boys compared with girls. Interestingly, it was found that boys perceived more social support from family members and friends than girls, while support from the PE teacher did not differ between genders. The lower levels of physical activity in girls should justify even higher social support towards girls than towards boys. In contrast to the above findings, the scores for attitudes and perceived barriers did not differ between genders in the present study, except for the fact that boys perceived doing sports and being active more as fun, compared with girls. Therefore, providing activities more directed towards the interests of girls seems needed.

Since significant gender differences were found for physical activity levels and for psychosocial correlates, clustering was evaluated in boys and girls separately. An important finding of the present study is that meaningful clustering was found in both genders. Boys were allocated to three clusters, while in girls four clusters of common reports were found. In both genders the highest scores for attitudes, perceived benefits, self-efficacy and social support clustered with the lowest scores for perceived barriers. In line with the literature on correlates ${ }^{14,21,22}$, boys and girls of these clusters reported the highest levels of physical activity. Striving to maintain these positive correlates is needed in these children in order to prevent a possible decline of physical activity. In contrast, in both genders one cluster was identified with clustering of low scores for attitudes, benefits, self-efficacy and support. It is not a surprise that these clusters comprised the children with the lowest scores for all activity measures. The intervention strategy for these clusters of 'negative' boys and girls should include all correlates by improving the attitudes towards physical activity, decreasing the barriers to be active, increasing the benefits and self-efficacy and improving social support to be active.

Besides these two clusters of the most active and the least active children in both genders, one cluster could be identified that was characterised mainly by common reports of high barriers. The 'hindered' boys reported higher activity levels than their counterparts from the 'negative' cluster with less barriers but lower scores for attitude, benefits, self-efficacy and support, except for the activity level during breaks at school. These findings lead us to believe that boys with a good attitude towards physical activity, a high perception of benefits, high selfefficacy and high social support are able to cope with the possible barriers, like e.g. having lack of time, sports being too expensive and the infrastructure being too far. On the other hand, the activity levels of the 'hindered' girls did not differ significantly from the activity levels of the girls with the most negative correlates. A possible explanation is that the hindered girls were also characterised by low selfefficacy scores, in contrast to the 'hindered' boys. It can be concluded that in the subgroup of 'hindered' girls the intervention strategy should include learning to cope with possible barriers and efforts to increase self-efficacy. In girls a fourth cluster, differentiated by low social support and average to low scores on most correlates, including perceived barriers, was identified. Interestingly, in this cluster of 'indifferent' girls with low perception of barriers, the second highest scores were found for all activity measures. Moreover, the frequencies of moderate and vigorous physical activity and the activity level during breaks were not lower than in the cluster of girls with the most positive correlates. The 'indifferent' girls reported also more sports at school and higher frequencies of moderate physical activity than the girls from the 'hindered' and the 'negatives' clusters. Apparently this subgroup of 'indifferent' girls can cope with barriers. As a result it can be concluded that in girls barriers play an important role. When the barriers to be active are low, girls who do not have a very positive attitude towards physical activity, do not perceive high benefits, receive low support to be active and have no high self-efficacy, do still accumulate relatively high levels of physical activity. 
However, as barriers will increase during the transition from childhood into adolescence, the intervention strategy in this subgroup of girls should include striving for a more positive attitude, a higher self-efficacy, more positive beliefs towards physical activity and in particular increasing social support in order to maximise the chance of maintaining an active lifestyle.

In the present study the highest score for perceived barriers in both genders was found for 'lack of time'. By offering and promoting physical activity possibilities for all children at school during after-school hours or at lunch breaks, this barrier and some others, like infrastructure too far' or 'lack of transportation', can be decreased. However, in a prior study ${ }^{23}$ we found that only $17 \%$ of the elementary schools in Flanders organise supervised sports during after-school hours or at lunch breaks.

The meaningful clustering found in the present study also indicates that efforts to prevent the physical activity decline during the transition into adolescence need to take all correlates into account. Interventions should endeavour to increase the perception of the benefits of an active lifestyle and to improve self-efficacy and positive attitudes by offering a wide selection of enjoyable, developmentally appropriate physical activity options. Encouragement and direct assistance to support the children's physical activity are also recommended. However, nagging or patronising, with possible negative effects on self-efficacy, has to be avoided. Moreover, since the present cluster analyses show that barriers play a major role, intervention strategies need to focus on the decrease of these barriers. Children also need to learn to cope with possible barriers by increasing specific problem-solving competencies.

In the present sample of boys and girls in Flanders, the clusters correlated with the most positive correlates and highest activity levels comprised the largest percentages of children ( $41 \%$ of the boys and 33\% of the girls). Apparently most 10- to 11-year-old children are characterised by positive correlates of physical activity. This is in line with the assumption that most children of the present study sample reach adequate levels of physical activity. Pupils participate in sports in or outside school for an average of $2 \mathrm{~h}^{-1} \mathrm{k}^{-1}$ and they also participate in about $2 \mathrm{~h}$ of PE weekly, which is mandatory. In addition, most pupils also perform unstructured physical activity like playing and active transport to school. Nevertheless, promotion efforts are needed to prevent the decline in physical activity and to reach the least active children. A negative finding of the present study is that $25 \%$ of the girls and $24 \%$ of the boys were allocated to the 'negatives', the least active cluster. As a result it can be concluded that almost a quarter of the children are characterised by rather negative correlates of physical activity. Special attention towards this group is needed, since these negative correlates towards physical activity will track until adulthood ${ }^{24}$ and may prevent the children from developing an active lifestyle.
While the present study shows that physical activity levels differed between children allocated to different clusters, sedentary behaviour did not. This can be explained by the fact that physical activity and sedentary behaviour are not two sides of a same $\operatorname{coin}^{2}$ and that correlates of physical activity are likely to differ from correlates of sedentary behaviours ${ }^{16}$. Accordingly in the present study it was found that boys accumulate not only higher levels of physical activity, but also higher levels of sedentary behaviour.

An important limitation of the present study is that the data relied on parent-assisted self-reports of sedentary behaviour, physical activity and psychosocial variables. Moreover, the validity of the measures for sedentary behaviour and psychosocial correlates can be questioned. Although a preliminary study evaluating the FPAQ in 11year-olds ${ }^{19}$ showed good reliability for all measures and acceptable validity for the physical activity indices, more objective measures of activity such as accelerometer data would have additional value. However, Trost et al. ${ }^{22}$ evaluated correlates of objectively measured physical activity in preadolescent youth and found consistent results with studies utilising self-reported activity. The strength of the present study was the investigation of physical activity, sedentary behaviour and psychosocial correlates in a large school sample and the evaluation of clustering of correlates in relation to physical activity and sedentary behaviour.

Future work is needed to cross-validate the clusters found in the present study in other independent samples of children. More research is also needed to further characterise the clusters of correlates of the least active children. To prevent the physical activity decline during the transition from childhood to adulthood, novel interventions need to be explored that focus on the children of the clusters with the most negative patterns of correlates.

\section{Acknowledgements}

This work was supported by a research grant from the Administration of Sport, Physical Education, and Open Air Activities (BLOSO) in Belgium. The authors are grateful to all the children and their parents who collaborated in the study.

Conflict of interest: None declared.

\section{References}

1 Bouchard C, Shepard R, Stephens T. Physical Activity, Fitness, and Health: International Proceedings and Consensus Statement. Champaign, IL: Human Kinetics, 1994.

2 Biddle S, Gorely T, Stensel D. Health-enhancing physical activity and sedentary behaviour in children and adolescents. Journal of Sports Sciences 2004; 22: 679-701.

3 Caspersen CJ, Merritt RK, Stephens T. International physical activity patterns: a methodological perspective. In: Dishman 
R, ed. Advances in Exercise Adberence. Champaign, IL: Human Kinetics, 1994; 73.

4 Steptoe A, Wardle J, Fuller R, Holte A, Justo J, Sanderman R, et al. Leisure-time physical exercise: prevalence, attitudinal correlates, and behavioral correlates among young Europeans from 21 countries. Preventive Medicine 1997; 26: $845-54$.

5 Myers L, Coughlin SS, Webber LS, Srinivasan SR, Berenson GS. Physical and sedentary activity in school children grades 5-8: The Bogalusa Heart Study. Medicine and Science in Sports and Exercise 1996; 28: 852-9.

6 Rowland TW. Adolescence: a 'risk factor' for physical inactivity. President's Council on Physical Fitness and Sports Research Digest 1999; 3: 1-8.

7 Trost SG, Pate RR, Sallis JF, Freedson PS, Taylor WC, Dowda $\mathrm{M}$, et al. Age and gender differences in objectively measured physical activity in youth. Medicine and Science in Sports and Exercise 2002; 34: 350-5.

8 Lefevre J, Philippaerts R, Delvaux K, Thomis M, Vanreusel B, Vanden Eynde B, et al. Daily physical activity and physical fitness from adolescence to adulthood: a longitudinal study. American Journal of Human Biology 2000; 12: 487-97.

9 Malina R. Tracking of physical activity and physical fitness across the lifespan. Research Quarterly for Exercise and Sport 1996; 67: 48-57.

10 National Association of Physical Education and Sports. Guidelines for Appropriate Physical Activity for Elementary School Children: Update 2003. Reston, VA: National Association of Physical Education and Sports, 2003.

11 Lobstein T, Frelut ML. Prevalence of overweight among children in Europe. Obesity Reviews 2003; 4: 195-200.

12 Jolliffe D. Extent of overweight among US children and adolescents from 1971 to 2000. International Journal of Obesity and Related Metabolic Disorders 2004; 28: 4-9.

13 Baranowski T, Anderson C, Carmack C. Mediating variable framework in physical activity interventions: how are we doing? How might we be doing better? American Journal of Preventive Medicine 1998; 15: 266-97.
14 Sallis J, Prochaska J, Taylor W. A review of correlates of physical activity of children and adolescents. Medicine and Science in Sports and Exercise 2000; 32: 963-75.

15 Sallis JF, Saelens BE. Assessment of physical activity by selfreport: status, limitations, and future directions. Research Quarterly for Exercise and Sport 2000; 71: 1-14.

16 Marshall S, Biddle S, Sallis J, McKenzie T, Conway T. Clustering of sedentary behaviors and physical activity among youth: a cross-national study. Pediatric Exercise Science 2002; 14: 401-17.

17 Seefeldt V, Malina RM, Clark MA. Factors affecting levels of physical activity in adults. Sports Medicine 2002; 32: 143-68.

18 Duncan TE, McAuley E. Social support and efficacy cognitions in exercise adherence: a latent growth curve analysis. Journal of Behavioral Medicine 1993; 16: 199-218.

19 Verstraete SJM, Cardon GM, Trost SG, De Bourdeaudhuij IMM. Comparison of the reliability and validity of a questionnaire to measure usual physical activity in children with and without the cooperation of a parent. Medicine and Science in Sports and Exercise 2003; 5: S337.

20 Deforche B, De Bourdeaudhuij I, Tanghe A, Hills AP, De Bode $\mathrm{P}$. Changes in physical activity and psychosocial determinants of physical activity in children and adolescents treated for obesity. Patient Education and Counseling 2004; 55: $407-15$.

21 US Department of Health and Human Services (DHHS). Physical Activity and Health: A Report of the Surgeon General. Atlanta, GA: US DHHS, Centers for Disease Control and Prevention, 1996; 234-5.

22 Trost SG, Pate RR, Ward DS, Saunders R, Riner W. Correlates of objectively measured physical activity in preadolescent youth. American Journal of Preventive Medicine 1999; 17: 120-6.

23 Cardon G, De Bourdeaudhuij I. Physical education and physical activity in elementary schools in Flanders. European Journal of Physical Education 2002; 7: 5-18.

24 De Bourdeaudhuij I, Sallis J, Vandelanotte C. Tracking and explanation of physical activity over a 7-year period. Research Quarterly for Exercise and Sport 2002; 73: 376-85. 